\title{
Analysis of shrinkage and creep effect for bridge widening based on TB-FEM method and experimental research
}

\author{
Keke Peng ${ }^{1, *}$, and Fangzhen $\mathrm{Wen}^{2}$ \\ ${ }^{1}$ Transportation and civil buildings college, Foshan University, Foshan 528000, China \\ ${ }^{2}$ Guangdong Highway Construction Co., Ltd., Guangzhou 510627, China
}

\begin{abstract}
Based on TB-FEM method and laboratory test, the influence of shrinkage and creep on the structure of widened bridge is studied. The shrinkage test uses C50 concrete and C50 double-mixture (steel polyester fiber) concrete to prepare the standard prism specimen, and the creep test uses the $15 \mathrm{~m}$ hollow slab which exactly has the same material, size, prestress and construction method of a real bridge as the creep test specimen. The strain-time curve obtained by shrinkage and creep is used to define the shrinkage and creep characteristics of the material, and Trost-Bazant is combined with finite element method to analyze the mechanical response of the new and old bridge splicing structure caused by shrinkage and creep. The result shows that under the condition of rigid splicing, the new bridge should be supported by the simply supported structure, and it is not suitable to use the same simply supported and continuous hollow slab as the original bridge. Theoretical analysis and example study show that combination of laboratory test and TB-FEM method can reasonably analyze the effect of shrinkage and creep on bridge widening, and provide a theoretical basis for the type selection of widening structure.
\end{abstract}

\section{Introduction}

Adopting of appropriate widening measures can improve the traffic capacity of old bridge and meet the needs of modem transportation. In the form of splice structure, there are three commonly used methods at present: (1) the deck width and bearing capacity of old bridge are insufficient. After a new half of bridge is built, the traffic will be diverted to this new half and the old bridge will be removed, and when the whole new bridge is built to the full width, the traffic will be diverted to the whole bridge. All traffic will be undertaken by the new bridge after reconstruction. (2) The deck width of the old bridge is insufficient. The old bridge structure is basically unchanged during the widening and the new bridge will be built on one side or both sides of the old bridge, while the old bridge continues to bear part of the traffic. After the reconstruction, the new bridge structure is independent from the old bridge structure. (3) The deck width of old bridge is insufficient, and the bearing capacity and stress in service stage meet the requirements of specification. After widening, the deck pavement of new and old bridge is spread continuously and jointly; in order to ensure

* Corresponding author: Pengkeke8481@126.com 
safety and comfort of driving, the compatibility of deformation of new and old bridge must be strictly guaranteed. For the case (1) and (2), the new and old bridge will not be under stress jointly, so the shrinkage and creep will not affect the widened structure; for the case (3), the new and old bridge will be under stress jointly and the shrinkage and creep of old bridge are basically completed, while the shrinkage and creep of new bridge are in progress, so the impact of shrinkage and creep on the new and old bridge widening structure must be considered[1-3].

Creep and shrinkage are among the basic characteristics of concrete which is a kind of viscous-elastic material, and they have a great influence on the bridge structure. They also have a long duration and complicated changing process, so it is not easy to control them [45]. In practical concrete structures, creep and shrinkage are mixed with temperature strain. In the analysis and calculation, temperature stress and temperature strain are often considered separately. Creep and shrinkage can be considered together [6]. There are three methods to analyze the influence of creep and shrinkage on structural internal force and component section stress: (1) Differential equation solution method [7]. (2) Algebraic equation solution method [8] and (3) stepwise analysis of finite element [9]. The first two methods are the solutions using the finite element stepwise analysis method. In this method, the time-varying nonlinear stress-strain relationship is used to consider the shrinkage and creep and it is necessary to solve the coupled-differential equations or algebraic equation; these equations are difficult to solve and the analytical solutions are long, so it is inconvenient to use them. Based on the experimental study, the shrinkage and creep characteristics of the material are obtained, and the characteristics are putted into the finite element model to analyze the influence of shrinkage and creep on the splicing structure of the new and old bridge.

\section{Research on the finite element calculation method for shrinkage and creep based on the Trost-Bazant-finite element method (TB-FEM method)}

The relationship between stress increment and strain increment caused by creep and shrinkage can be expressed by the Dischinger method [10] and Trost-Bazant method [11]. This paper is based on the TB method. The relationship between stress and strain increment is expressed in a more precise form as follows by taking $t_{i}$ as the calculation time:

$$
\begin{aligned}
\Delta \varepsilon_{c s}\left(t_{i}, t_{i-1}\right)= & \frac{\Delta \sigma_{c s}\left(t_{i}, t_{i-1}\right)}{E\left(t_{i-1}\right)}\left[1+\chi\left(t_{i}, t_{i-1}\right) \varphi\left(t_{i}, t_{i-1}\right)\right] \\
& +\left\{\sum_{j=1}^{i-1} \frac{\Delta \sigma\left(t_{j}\right)}{E\left(t_{j}\right)}\left[\varphi\left(t_{i}, t_{j}\right)-\varphi\left(t_{i-1}, t_{j}\right)\right]+\Delta \varepsilon_{s}\left(t_{i}, t_{i-1}\right)\right\}
\end{aligned}
$$

where: $\Delta \varepsilon_{c s}\left(t_{i}, t_{i-1}\right)$ and $\Delta \sigma_{c s}\left(t_{i}, t_{i-1}\right)$ - strain increment and stress increment caused by the creep and shrinkage in the period from $t_{i-1}$ to $t_{i} ; \Delta \sigma\left(t_{j}\right)$ - stress increment at the time $t_{j} ; \Delta \varepsilon_{s}\left(t_{i}, t_{i-1}\right)$ - shrinkage strain increment occurred in the period from $t_{i-1}$ to $t_{i}$; $E\left(t_{j}\right)$ - the modulus of elasticity at the time $t_{j}$.

In the finite element analysis of the creep and shrinkage of concrete bridges, the process from the beginning of construction to completion and until the completion of shrinkage and creep can be divided into several calculation stages, and each calculation stage can be divided into several appropriate time intervals. The structures built in each computation stage are divided into several units, so that the concrete of each unit has the uniform creep 
and shrinkage characteristics. The data simulation test shows that if the concrete creep coefficient and shrinkage strain are simulated as the multiple exponential coefficient expressions by taking $e$ as the base, the memory consumption of computer will be greatly reduced and the calculation speed will be quicker when the finite element analysis is used for calculation. The above theory is the basic idea of the TB-FEM method. In this paper, the Workbench program in ANSYS12 software is used to conduct the iterative analysis on the influence of shrinkage and creep on the widening bridge by finite element method.

\section{Project background}

The old bridge used as an example adopts the $10 \times 15=150 \mathrm{~m}$ cross-structure continuous hollow slab, which has a bridge width of $157.75 \mathrm{~m}$ and cantilever of $37.5 \mathrm{~cm}$; it is composed of 15 slabs, as shown in the figure 1.

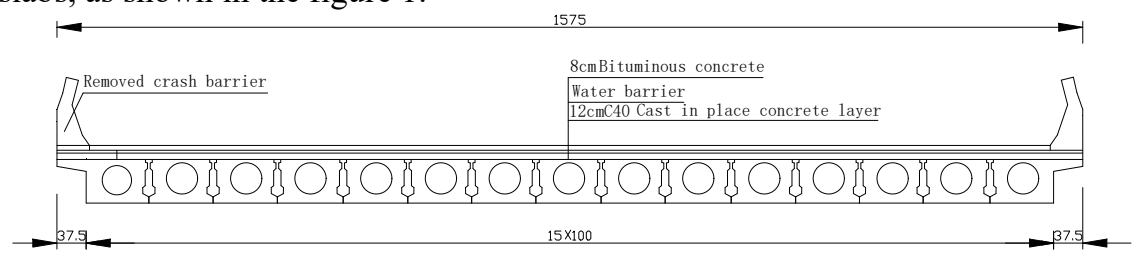

Fig. 1. Cross Section of Old Bridge.

Three longitudinal widening structure schemes are given for the original structure of the bridge used as example. Scheme I: the simply supported structure is used for the new bridge to realize rigid splicing with the original bridge and end cross beam is arranged at the support location; scheme II: the simply supported structure is used for the new bridge to realize rigid splicing with the original bridge and end cross beam is not arranged at the support location; Scheme III: rigid splicing of new bridge is implemented by using the same structural continuous hollow slab with the original bridge, and end cross beam is arranged at the support location. Finite element model is established for each of the above schemes. The new bridge takes account of the shrinkage and creep of concrete, and the old bridge does not consider the shrinkage and creep of concrete to compare and select the optimum scheme.

\section{Concrete shrinkage and creep test}

\subsection{Concrete shrinkage test}

According to the requirements of the specification GB/T50082-2009[12], this test uses the C50 concrete and C50 double-mixture concrete (steel fiber and polyester fiber), and 2 groups of specimen are made for each type of concrete for purpose of test. Each group consists of 3 specimen which are $100 \mathrm{~mm} \times 100 \mathrm{~mm} \times 515 \mathrm{~mm}$ prism concrete specimen, and these specimens are used for testing of the length shrinkage of concrete specimen not caused by external force under the standard temperature and moisture condition. The specimen will be removed from the standard curing room at the age of 3 days (starting from water adding into concrete in the mixing station) and immediately moved into the constant temperature and humidity chamber at a temperature of $(20 \pm 2){ }^{\circ} \mathrm{C}$ and relative humidity (60 \pm 5 ) $\%$ to test the initial length. After that, measure the strain readings (start from the date of moving into the constant temperature and humidity chamber, and the age shall be determined according to the actual situation) at the specified time interval $(1 \mathrm{~d}, 3 \mathrm{~d}, 7 \mathrm{~d}, 14 \mathrm{~d}$, $28 \mathrm{~d}, 45 \mathrm{~d}, 60 \mathrm{~d}, 90 \mathrm{~d}, 120 \mathrm{~d}, 150 \mathrm{~d}, 180 \mathrm{~d}, 240 \mathrm{~d}, 300 \mathrm{~d}$ and $360 \mathrm{~d})$. The curve for the change of 
shrinkage strain of each concrete specimen with time can be obtained according to the measured shrinkage strain data of concrete specimen, as shown in the figure 2.

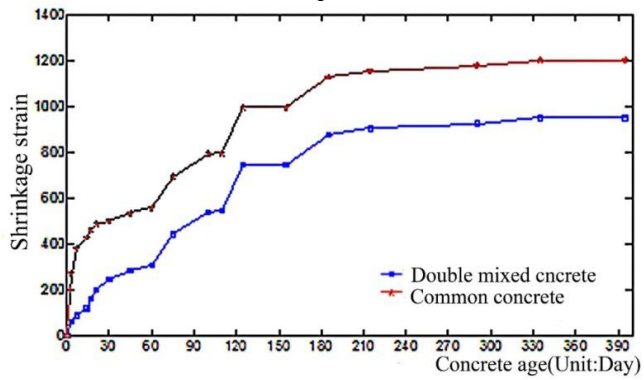

Fig. 2. Concrete Shrinkage Strain Time Curve.

Through the analysis of data and shrinkage strain-time curve obtained from the concrete shrinkage test, it is found that the shrinkage strain of concrete increases with time, and the shrinkage deformation of concrete specimen is faster in the early stage: the shrinkage deformation of most specimen accounts for a large percentage up to $70 \%$ in the total shrinkage deformation in 1 month after the preparation of specimen. The concrete shrinkage can be effectively reduced by adding a certain amount of steel fiber and polyester fiber in concrete.

\subsection{Concrete creep test}

According to the test method specified in the specification GB/T50082-2009 [12], creep and shrinkage tests of concrete belong to the category of long-term durability of concrete. The creep test of concrete is performed by using the $15 \mathrm{~m}$ hollow slab (a piece of middle plate) which exactly has the same material, size, pre-stress and construction method with the real bridge as the creep test specimen. The test beam is designed according to the partial pre-stressed A-class components and constructed by using the pre-tensioning method; the concrete is C50 concrete; the pre-stressed steel strand has a nominal diameter of $\phi^{s} 15.2 \mathrm{~mm}$, nominal area $140 \mathrm{~mm}^{2}$, tensile strength standard value of $f_{p k}=1860 \mathrm{MPa}$ and modulus of elasticity $E_{p}=1.95 \times 10^{5} \mathrm{MPa}$. The common steel bar is hot rolled HRB335 steel. Electronic level is used for the specimen to measure the displacement of the inverted arch in the hollow slab, and displacement strain sensor is used to measure the creep strain changes of the main girder in the mid-span.

Take the four angle points at the upper left comer, lower left comer, upper right comer and lower right comer on the cross section of the mid-span as the measuring points. In order to intuitively reflect the difference between the actual creep values and the theoretical values of the test beams at each measurement point, the actual creep strain data of the test beam and the theoretical values are plotted in a time history curve for purpose of comparison and analysis, as shown in figure 3.

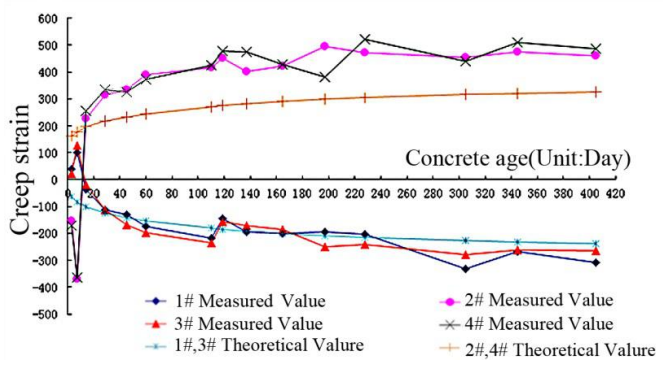

Fig. 3. Creep Strain-Time Curve of Test Beam. 


\subsection{Conclusion of shrinkage and creep test}

(1) The shrinkage deformation of concrete specimen is faster in the early stage, and the shrinkage deformation of most specimen accounts for a large percentage up to $70 \%$ in the total shrinkage deformation in 1 month after the preparation of specimen. (2) Due to the existence of pre-stress, the creep strain of test beam shows a trend of gradual increase in the initial period and reversed development in the later period, and the actual creep development curve is different from the theoretical creep strain calculated by the creep coefficient stipulated in the JTG D62-2004. (3) At the $\varepsilon(t)$ moment, the strain of the concrete member can be expressed as follows:

$$
\varepsilon(t)=\varepsilon_{i}(\tau)+\varepsilon_{c}(t)+\varepsilon_{s}(t)+\varepsilon_{T}(t)=\varepsilon_{\sigma}(t)+\varepsilon_{n}(t)
$$

where, $\varepsilon_{i}(\tau)$ is the initial strain at loading time; $\varepsilon_{c}(t)$ is creep strain at the $t>\tau$ time, $\varepsilon_{s}(t)$ is the shrinkage strain, and $\varepsilon_{T}(t)$ is the temperature strain.

$\varepsilon_{\sigma}(t)=\varepsilon_{i}(\tau)+\varepsilon_{c}(t)$ is the strain generated by the stress; $\varepsilon_{n}(t)=\varepsilon_{s}(t)+\varepsilon_{T}(t)$ is the non-stress strain.

After entering the shrinkage and creep strain relationship; $\varepsilon_{s, c}(t)=\varepsilon_{s}(t)+\varepsilon_{c}(t)$, obtained from test into the finite element model, the related shrinkage and creep parameters in the theoretical calculation can be corrected to obtain the theoretical model which is closer to the actual working state, which makes the comparison analysis between the theoretical calculation and measured date become more reasonable.

\section{ANSYS simulation analysis result of shrinkage and creep}

\subsection{Finite element model}

The automatic grid division method is used to divide into different units and these units are the tetrahedron units without intermediate node. The number of units and nodes of the whole bridge is shown in the table 1, while the entity model is shown in the figure 4 (here only list the finite element model for the Scheme I due to the space limit).

Table 1. Number of Units and Nodes of each Scheme.

\begin{tabular}{|c|c|c|}
\hline Scheme & Nodes number & Elements number \\
\hline Scheme I & 367029 & 159050 \\
\hline Scheme II & 344045 & 147833 \\
\hline Scheme III & 367994 & 159782 \\
\hline
\end{tabular}

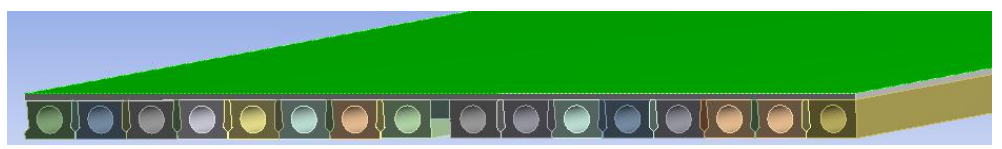

Fig. 4. Finite Element Mesh Division of Entity Model of Scheme I.

\subsection{Simulation analysis result}

The TB-FEM method is used to analyze the influence of shrinkage and creep on each scheme and the main calculation results are extracted as figure 5.

The three schemes in aspects of the maximum shrinkage, creep strain and its changes along the beam length when $\mathrm{t}=10$ years. As shown in figure 5 , in term of the maximum 
shrinkage and creep stress of the cross section in the 10th year, the Scheme III has the maximum stress, Scheme I has the medium stress and scheme II has the minimum stress; Scheme I and 2 have the similar stress. The shrinkage and creep stress values of scheme III are much larger than those of the other two schemes. The stress value of scheme III has a trend of gradual increase from middle to both ends, while the stress values of scheme I and 2 are relatively unstable, which means that the use of simply supported structure for bridge expansion can effectively reduce the spatial transfer of shrinkage and creep and decrease the stress value of shrinkage and creep. The stress values of the three schemes are basically consistent at the ends, which is because the scalability at ends can mitigate the influence of shrinkage and creep.

Figure 6 shows the stress comparison of the new and old bridge splicing belts in the 3 schemes. As shown in the figure 6, the scheme III has the maximum stress at the splicing belt, scheme II has the medium stress and Scheme I has the minimum stress. The effect of shrinkage and creep is larger in the initial period of bridge completion, and its growth rate gradually slows down with time. The stress values of splicing belts in the Scheme I, 2 and 4 increases slightly with time, but the growth rate is decreased with time. The influence of shrinkage and creep difference on the splicing belts of bridge is higher than that on the new bridge.

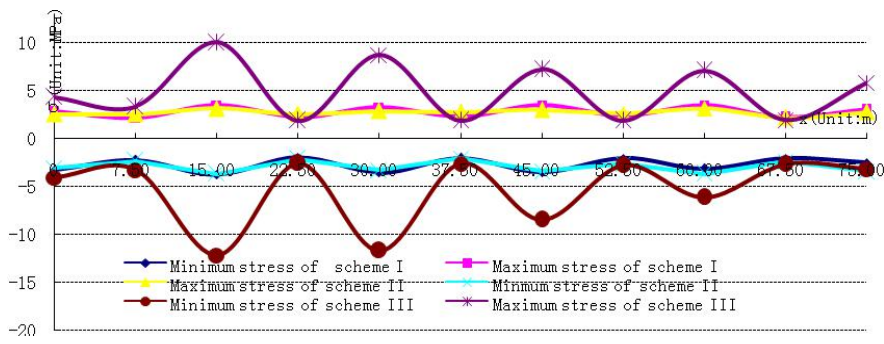

Fig. 5. Distribution of Maximum Stress along the Beam Length (10 years).

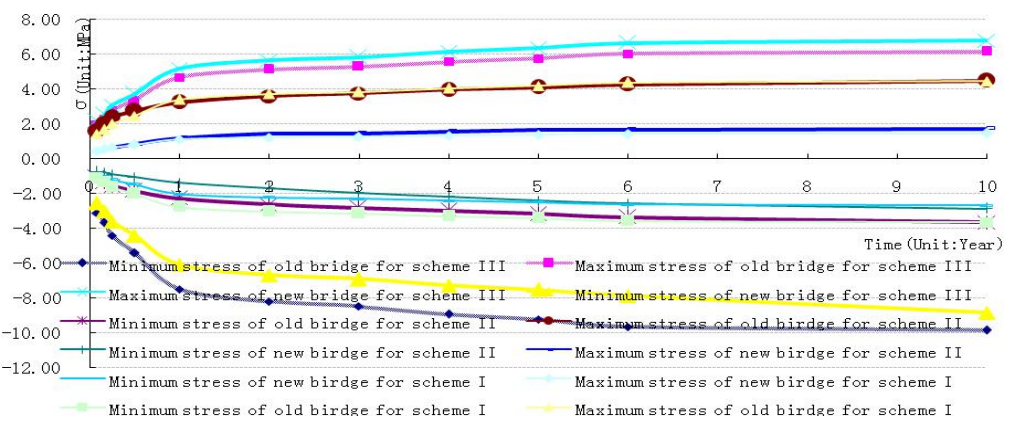

Fig. 6. Time-varying Diagram for the Maximum Stress at the Splicing Belts (10 years).

It can be seen from the above calculation that the stress value generated by the shrinkage in the Scheme III is too large, which will cause damage especially to the integrated layer; according to the calculation and comparison, the Scheme III cannot be considered as a rigid splicing scheme for the continuous hollow slab beam of a long joint structure.

\section{Conclusion and prospect}

The shrinkage test uses C50 concrete and C50 double-mixture concrete to make the standard prism concrete specimen; the creep test uses the $15 \mathrm{~m}$ hollow slab which has the same material size, pre-stress and construction method with the real bridge. The strain-time 
curve obtained by shrinkage and creep is used to define the shrinkage and creep's characteristics of the material, and the TB method and finite element method are combined to analyze the mechanical response of the new and old bridge splicing structure caused by shrinkage and creep. The research shows that under the condition of rigid splicing, the new bridge should be supported by the simply supported structure, and it is not suitable to use the simply supported and continuous hollow slab. This study can provide a theoretical basis for the splicing time of new and old bridge as well as the type selection of new bridge structure. As the new and old bridge splicing scheme includes the type selection of new bridge structure, comparison and selection of transverse splicing scheme, comparison and selection of splicing time, etc., the proposed method in this project only studies the problem of type selection of new bridge structure under the condition of transverse rigid splicing of new and old bridge after considering the factor of shrinkage and creep difference. The identification of other factors and the decision of splicing scheme need further study.

\section{Acknowledgments}

The author would like to acknowledge the support from the Natural Science Foundation of China (Project number: 51608119).

\section{References}

1. Du Huidong 2017 Shrinkage and Creep \& Foundation Settlement Theory based Research for Bridge Expansion Program (Kumming: Thesis of Kunming University of Science and Technology).

2. TuBing, Fagzhi 2016 Analysis of Shrinkage and Creep Effects on Newly-built and Existing Concrete Slab Bridge after Lateral Jointing (China: China Journal of Highway and Transportation) Vol 29 No10 pp 66-76.

3. Wang P, Hu W, Zhang C. 2015 Method to Analyze the Effect of Concrete Shrinkage and Creep on Widened T-Beam Bridges International Conference on Intelligent Transportation, Big Data and Smart City.(Las Palmas de Gran Canaria) pp 511-514.

4. Tu B, Fang Z, Dong Y, et al. 2017 Time-variant reliability analysis of widened deteriorating pre-stressed concrete bridges considering shrinkage and creep (England: Engineering Structures) Vol $153 \mathrm{pp}$ 1-16.

5. Sagara A, Pane I. 2015 A Study on Effects of Creep and Shrinkage in High Strength Concrete Bridges (England: Procedia Engineering) Vol 125 pp 1087-1093.

6. Wang J, Yao Y, Su M.2017 Coupling Effect between Concrete Creep, Shrinkage and Temperature on Long Span Box Girder (Shijiazhuang: Bridge Journal of Shijiazhuang Tiedao University) Vol 30 Nol pp 1-7.

7. Yang Yingen. 2016 Differential Equation Method for Effects of Creep and Shrinkage in Steel-Concrete Composite Beam ( Kumming: Thesis of Kunming University of Science and Technology).

8. Han Chunxiu, Zhou Donghua, Yang Yanhua, Chen Xu,Yao Kaicheng 2016 Use of an algebraic constitutive equation to calculate the stress redistribution due to creep and shrinkage of composite beams (Harbin: Journal of Harbin Engineering University) Vol 37 No 8 pp 1041-1049.

9. Huang Ying, Gao Jie 2016 Computational Analysis and Finite Element Simulation Study on Shrinkage and Creep of Pre-stressed Concrete Structures (Sichuan: Journal 
of Sichuan University of Science \& Engineering (Natural Science Edition)) Vol 29 No 3 pp 75-80.

10. Zdeněk P. Bažant, Liisa Panula 1978 A note of amelioration of the creep function for "improved dischinger method" (England: Cement \& Concrete Research) Vol 8 No 3 pp 381-386.

11. Zdeněk P. Bažant 2016 Random Creep and Shrinkage in Structures: Ampling Journal of (England: Structural Engineering) Vol 111 No 5 pp 1113-1134.

12. Ministry of Housing and Urban-Rural Development of the People's Republic of China ( MOHURD ) General Administration of Quality Inspection and Quarantine of the People ' s Republic of China 2009 Standard for test methods of long-term performance and durability of ordinary concrete (State Standard of the People's Republic of China : 2009-11-30 Published, 2010-07-01 Put into effect). 